\title{
Development of Modal Test Techniques for Validation of a Solar Sail Design
}

\author{
James L. Gaspar ${ }^{*}$ \\ NASA Langley Research Center, Hampton, VA, 23681 \\ Troy Mann ${ }^{\dagger}$ and Vaughn Behun ${ }^{\ddagger}$ \\ Swales Aerospace, Hampton, VA, 23681 \\ and \\ W. Keats Wilkie ${ }^{\S}$ and Richard Pappa ${ }^{* *}$ \\ NASA Langley Research Center, Hampton, VA, 23681
}

\begin{abstract}
This paper focuses on the development of modal test techniques for validation of a solar sail gossamer space structure design. The major focus is on validating and comparing the capabilities of various excitation techniques for modal testing solar sail components. One triangular shaped quadrant of a solar sail membrane was tested in a 1 Torr vacuum environment using various excitation techniques including, magnetic excitation, and surfacebonded piezoelectric patch actuators. Results from modal tests performed on the sail using piezoelectric patches at different positions are discussed. The excitation methods were evaluated for their applicability to in-vacuum ground testing and to the development of onorbit flight test techniques. The solar sail membrane was tested in the horizontal configuration at various tension levels to assess the variation in frequency with tension in a vacuum environment. A segment of a solar sail mast prototype was also tested in ambient atmospheric conditions using various excitation techniques, and these methods are also assessed for their ground test capabilities and on-orbit flight testing.
\end{abstract}

\section{Introduction}

$\mathrm{R}$ evolutionary concepts for ultra-lightweight gossamer space structures are being studied by NASA ${ }^{1}$. In the next few years, prototype hardware will be produced and will require structural testing and validation. Many of these space structures are expected to have large sections of pre-tensioned flat membranes that will need to be vibration tested and validated ${ }^{2}$. Their delicate nature requires the use of novel excitation methods and noncontacting structural measurement techniques. Laser vibrometry for vibration measurement with surface-bonded piezoelectric patches for excitation is one candidate technology for this purpose.

The research reported in this paper was conducted to begin to address the technical challenges and requirements of modal testing a solar sail design ${ }^{3-5}$, as shown in Fig. 1. Specific objectives of this work are to investigate the effectiveness (i.e., accuracy, precision, repeatability, etc.) of laser vibrometer measurements obtained on a thin pretensioned solar sail membrane actuated with surface-bonded piezoelectric patches at various positions on the membrane and to compare this technique with more traditional modal test methods. In addition, a segment of a solar sail mast (Fig. 2) is tested using similar techniques, with piezoelectric actuators bonded to the longerons.

\footnotetext{
${ }^{*}$ Research Engineer, Structural Dynamics Branch, NASA Langley Research Center, MS 230, Hampton, VA 23681, Member AIAA.

${ }^{\dagger}$ Aerospace Engineer, Engineering and Design Group, Swales Aerospace, Hampton, VA 23681, Member AIAA.

${ }^{*}$ Lead, Engineering and Design Group, Swales Aerospace, Hampton, VA 23681, Member AIAA.

$\S$ Senior Research Aerospace Engineer, U.S. Army Research Laboratory, Vehicle Technology Directorate, NASA Langley Research Center, MS 230, Hampton, VA 23681, Member AIAA.

${ }^{* *}$ Senior Research Engineer, Structural Dynamics Branch, NASA Langley Research Center, MS 230, Hampton, VA 23681, Member AIAA.
} 


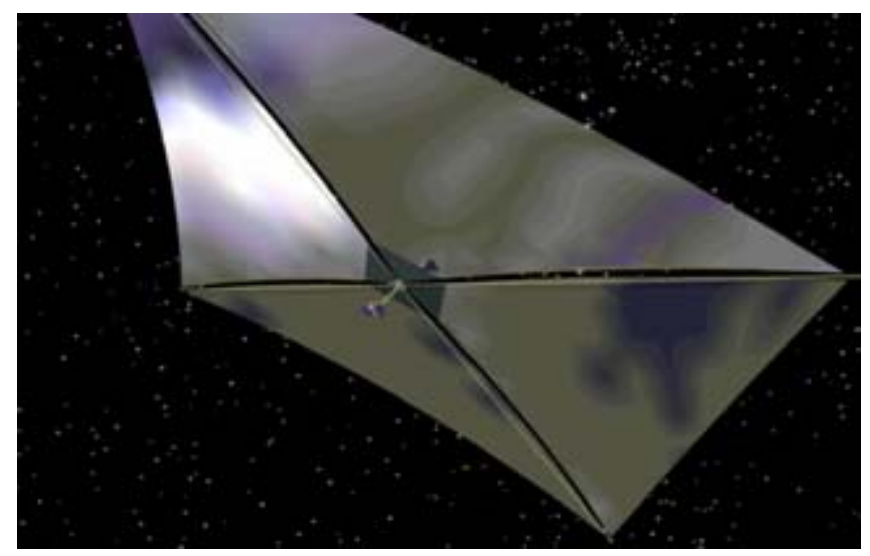

Figure 1. Solar Sail Concept with Masts and Sail Quadrants

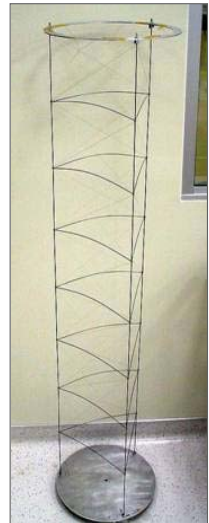

Figure 2. Mast Segment

\section{Solar Sail Quadrant In-vacuum Tests}

\section{A. Description of Test Article}

The test specimen (Fig. 3) is one triangular shaped quadrant of a solar sail membrane measuring 10-meters along the long edge. This particle sail was provided by SRS Technologies and is made of an aluminized 7-micron mylar membrane with integrated shear compliant borders and a stiffening cord along each edge. All three corners of the article are attached with thin wire through a grommet. Linear actuators at the two halyard corners are used to precisely preload the membrane. Force gauges are used to determine tension at each of the three corners. The tensioning devices are supported by aluminum plates mounted to a stiff truss structure.

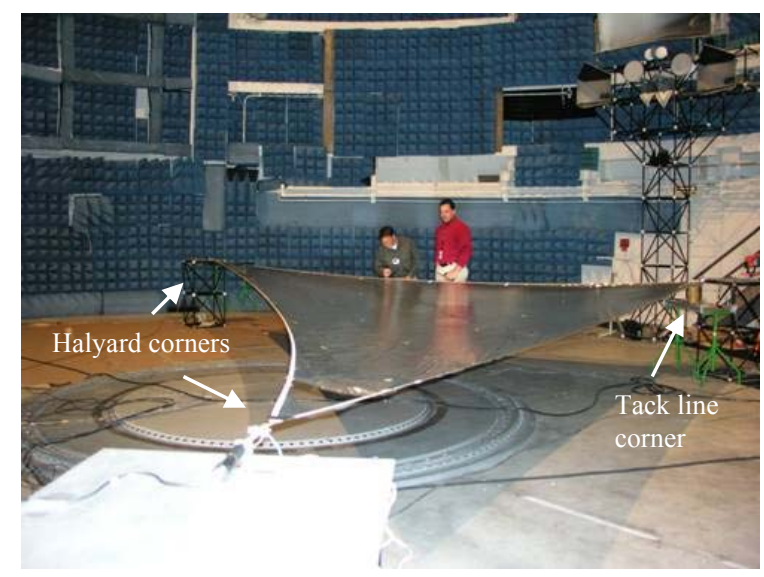

Figure 3. Sail Quadrant Experimental Test Setup

\section{B. Sail Excitation Methods}

The test article is excited using two types of excitation methods. The first was a non-contacting magnetic excitation method where an electro-magnet is used to provide out-of-plane motion to the sail via moving a small magnet fixed to the tack-line corner of the sail membrane ${ }^{6}$. The other method used ceramic fiber based piezoelectric patches applied to the edge region of the sail (normally referred to as a cord). The ceramic based patches were developed at NASA Langley and are denoted MFC's (Macro Fiber Composites) ${ }^{7}$. Similar actuators have been demonstrated to work on smaller scale membranes in previous experiments ${ }^{8}$. For this study, actuators were placed at various positions on the membrane to determine their capability for exciting the membrane modes. Figure 4 shows the piezoelectric patches used and the electromagnetic exciter. A bimorph MFC configuration was required, in which two MFCs are bonded to each other and driven out-of-phase to provide an out-of-plane motion. Unlike the 
magnetic exciter, which is non-contacting, the MFCs are surface-bonded to the top surface of the cord region of the sail with 3M 501FL double-backed adhesive transfer tape with an adhesive layer thickness of 51 microns. The MFC patches could easily be removed and reused for other tests. Strain gage wires are soldered to the MFC leads. For all tests performed, the actuator wires were carefully secured to minimize their effect on the sail membrane vibrations.

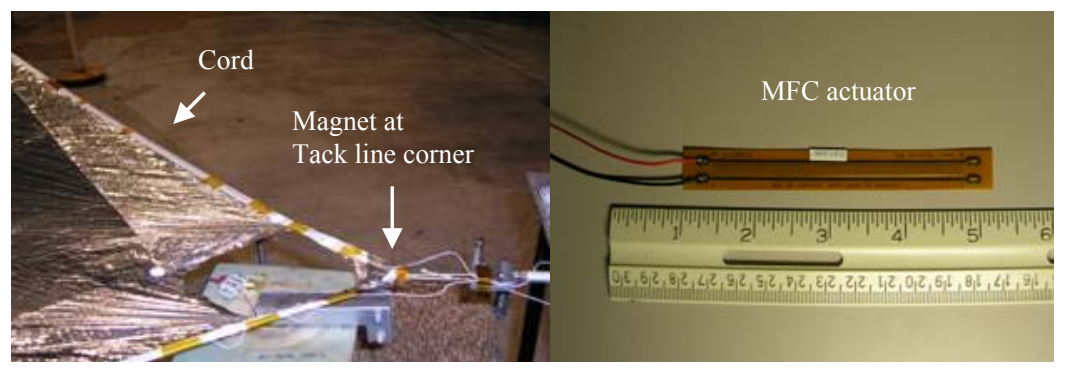

Figure 4. Magnetic Exciter and Piezo Actuator

\section{Sail Actuator Locations}

The surface-bonded bimorph MFC configuration provides a small out-of-plane disturbance on the membrane due to the bending caused by the shear force created at the interface between the two MFCs when driven out-of-phase with high voltage. This bending can be seen as a small bulge on the surface of the membrane at the actuator location. The out-of-plane disturbance is capable of exciting the vibration modes of the structure when the actuator is strategically positioned on the membrane. Piezoelectric patches are most effective when placed at strain antinodes, i.e. the strain in the direction of the actuator is high. This is different from a traditional shaker modal test, where the shaker is most effective at displacement anti-nodes. Many actuator locations were tested to determine how best to excite various modes of the membrane. The various actuator patch locations, shown in Fig. 5, included excitation near the corners as well as at the center cord region of the sail.

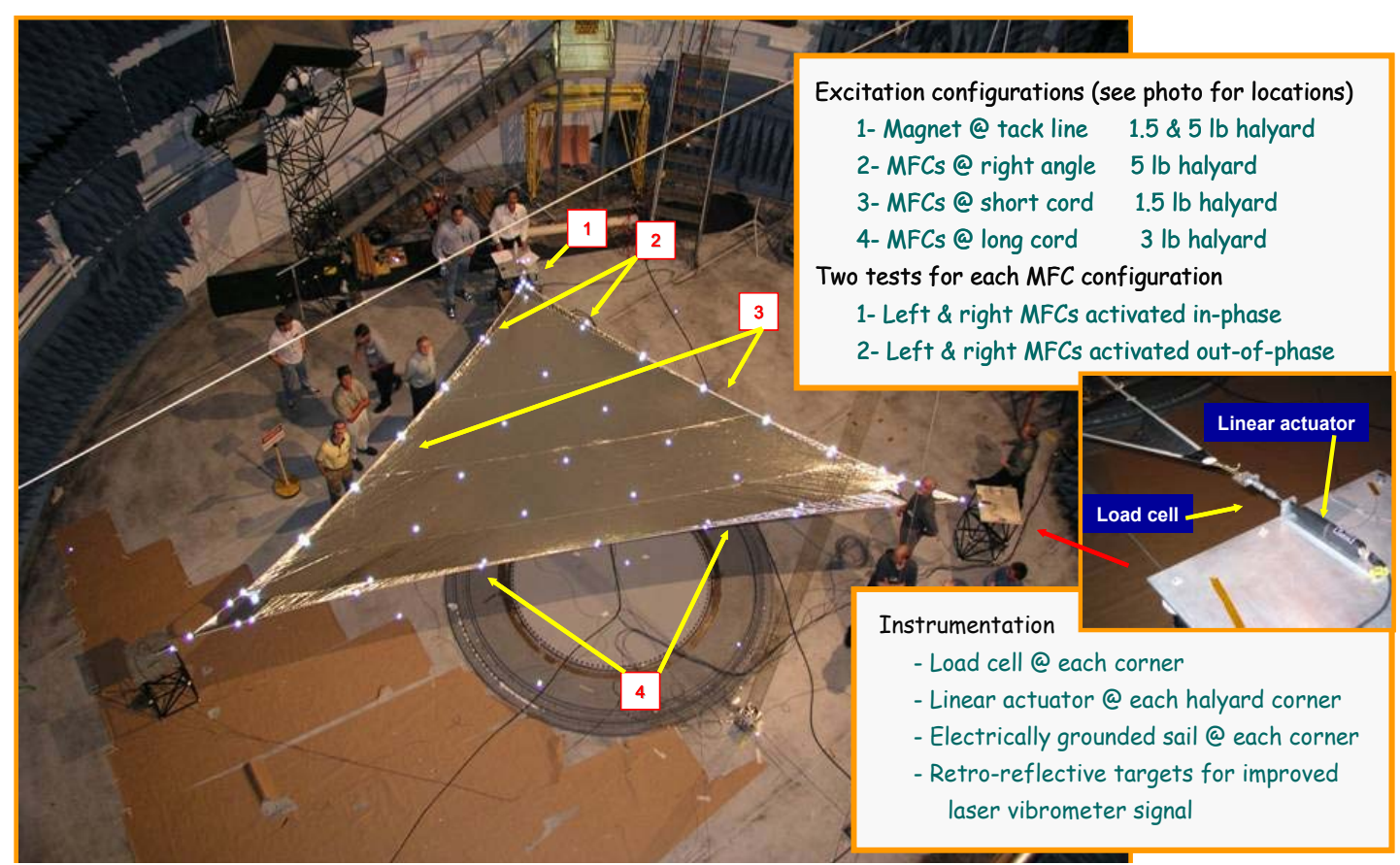

Figure 5. Actuator Location Configuration 


\section{Sail Vibration Measurement Method}

A Polytec PSV-300-H scanning laser vibrometer system is used to measure vibration modes of the test article (Fig. 6). To provide accurate measurements, 28 retro-reflective dots are adhered to the sail membrane in a grid pattern at even spacing to allow for increased reflection of the laser beam to the laser vibrometer. To protect the delicate laser scan head from the vacuum environment, a pressurized canister was fabricated to place the scanner inside. The canister has a window port from which the scanner can view the test article. A temperature sensor inside the canister is controlled by a switch that will automatically shut the scan head down at 100 degree F. Forced air flow is used to cool the inside of the canister. One Kevlar line is used to hoist the canister to 50 feet above the sail for the required scan range. Another kevlar line is used to hoist the canister, while 3 lines restrain canister against side motion. One other line restrains power cables, sensor wires, and the air flow tubes. The Polytec software is used to view frequency response functions (FRF's) and operating deflection mode shapes.

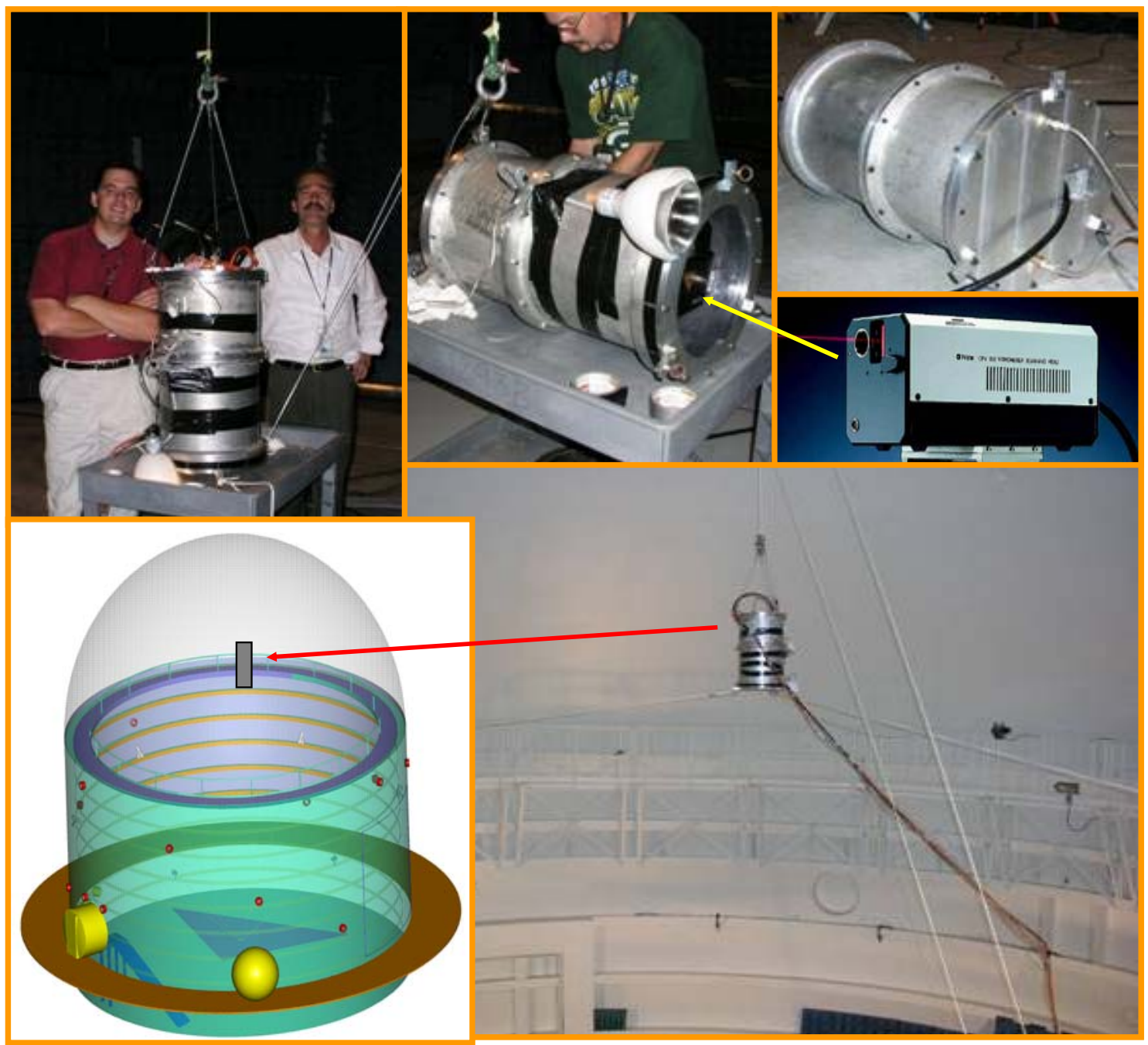

Figure 6. Laser Vibrometer Suspended Above Test Article

\section{E. Sail Test Description}

All vibration measurements were made under vacuum conditions with a pressure of 1 Torr in the 16-meter vacuum chamber in the Structural Dynamics Laboratory at the NASA Langley Research Center. Tests were performed with the membrane at various tension levels. All tests applied a periodic chirp input signal with a 
bandwidth of 0 to $8 \mathrm{~Hz}$ to the actuators. The periodic chirp voltage signal from the signal generator was used as the reference for the FRF calculations. To actuate the piezoelectric patches, the signal is amplified by 200 volts-per-volt with a Trek amplifier (Model PZD700) to produce a maximum input voltage of 1400 volts peak-to-peak ( \pm 700 volts). The FRF's are computed using 5 ensemble averages and 512 frequency lines from $0-8 \mathrm{~Hz}$.

\section{Discussion of Sail Test Results}

As with any modal test, accurate positioning of the actuators was found to be crucial for obtaining high quality modal data. A pretest finite element model was used to predict high strain areas at each resonance. The results from testing the membrane with various actuator configurations are discussed below.

\section{A. Test Configuration 1 - Magnet at tack-line}

Figure 7 shows the coherence and mode shapes for the first four dominant modes excited using a single magnetic exciter positioned at the 90 degree corner of the sail referred to as the tack-line. The coherence measurement indicates the degree of correlation between the input signal and the response signals. The coherence is used to assess the quality of the mode shapes obtained at resonance. Values above 0.9 over a large portion of the frequency spectrum are considered to be good. The coherences show that all four of the modes are excited well with smooth symmetric mode shapes. The few low coherence values occur near anti-resonances, where the signal-to-noise ratio is poor and low coherence is acceptable. The mode shapes also corresponded well with those predicted by the pretest finite element analysis.

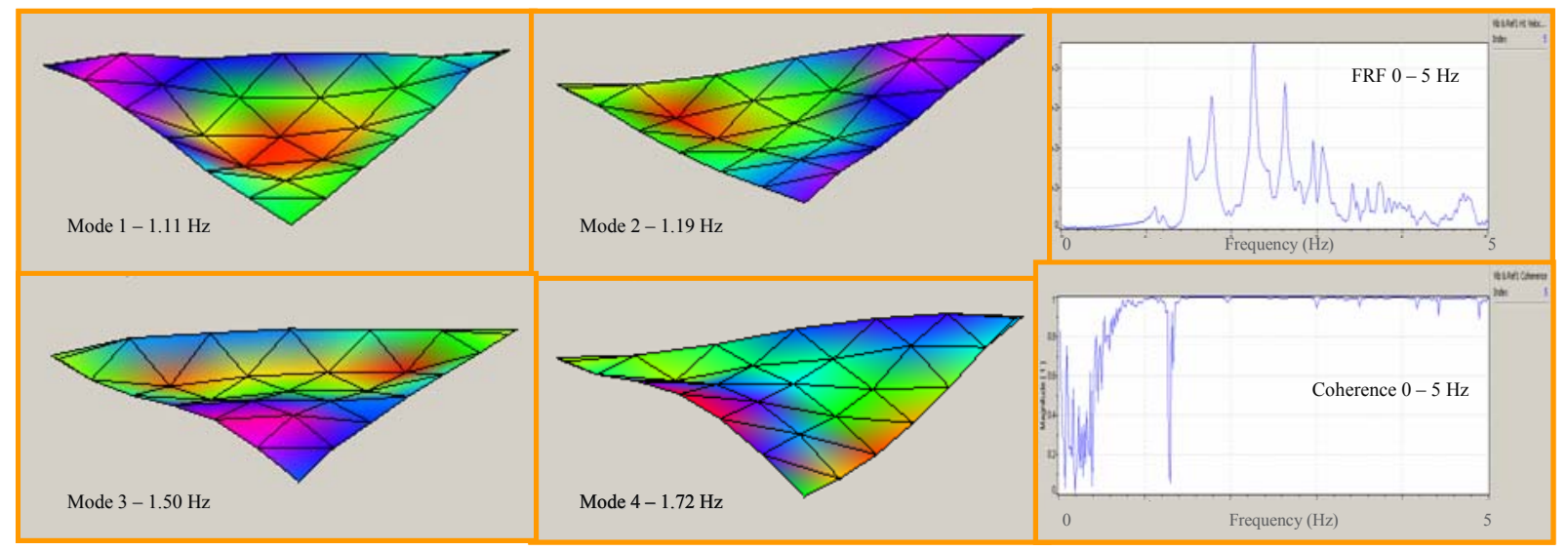

Figure 7. Coherence and Mode Shapes Obtained from Test Configuration 1

\section{B. Test Configuration 2 - MFCs at Right Angle}

Test configuration 2 uses actuation by MFCs at the right angle corner location near the tack-line. Figure 8 shows that the first two modes were excited well with good coherence, and these modes also corresponded well with analysis results. In this case the frequencies are somewhat higher due to the higher halyard corner load of $5 \mathrm{lbs}$. 

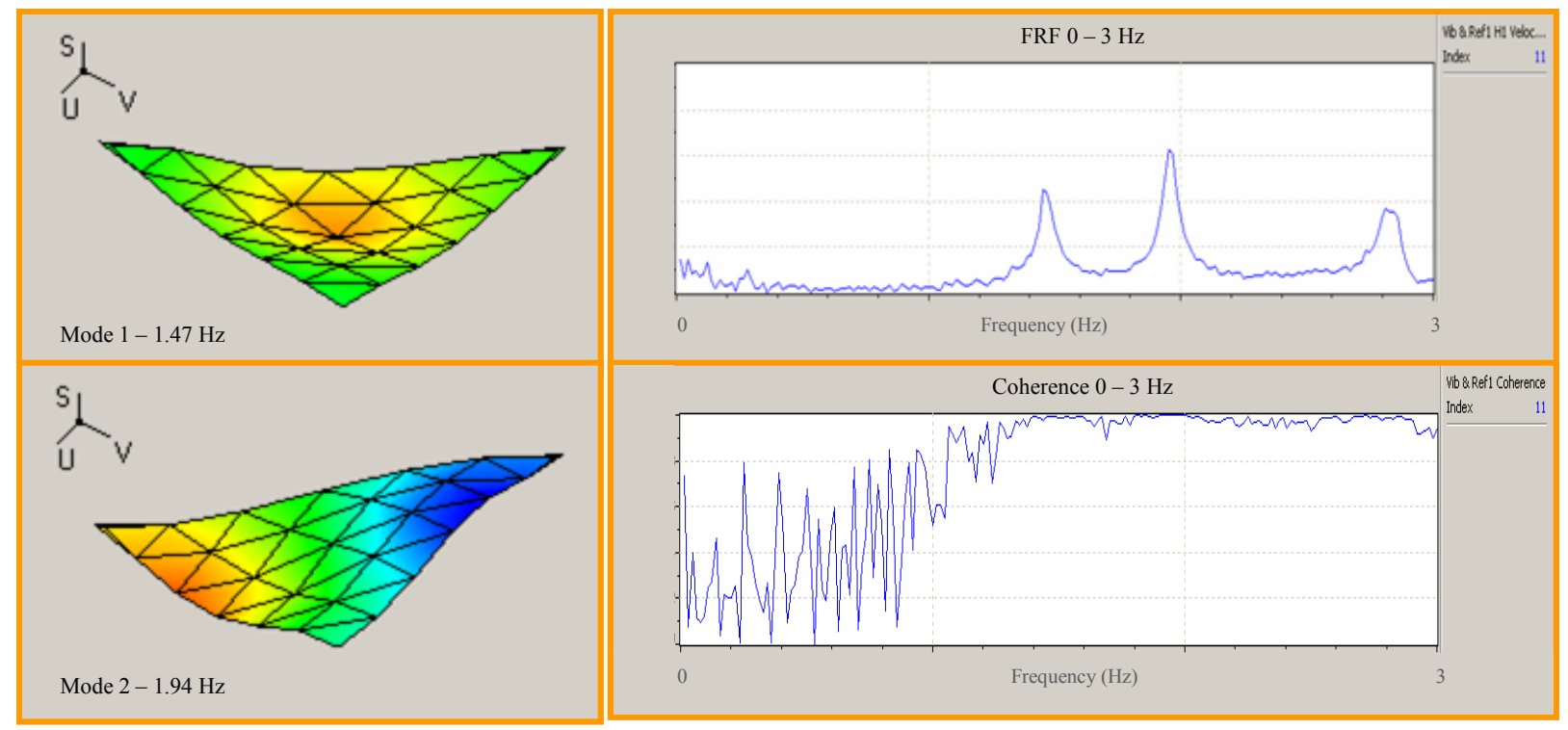

Figure 8. Coherence and Mode Shapes Obtained from Test Configuration 2

\section{Test Configuration 3 - MFCs at Short Cord Center}

Test configuration 3 is when the MFCs at the short cord center are actuated. Figure 9 shows that the third mode was excited well when the actuators are activated in-phase with one another, while the fourth mode is well excited when the two actuators are driven out-of-phase. This can be expected due to the symmetric and anti-symmetric nature of these modes.

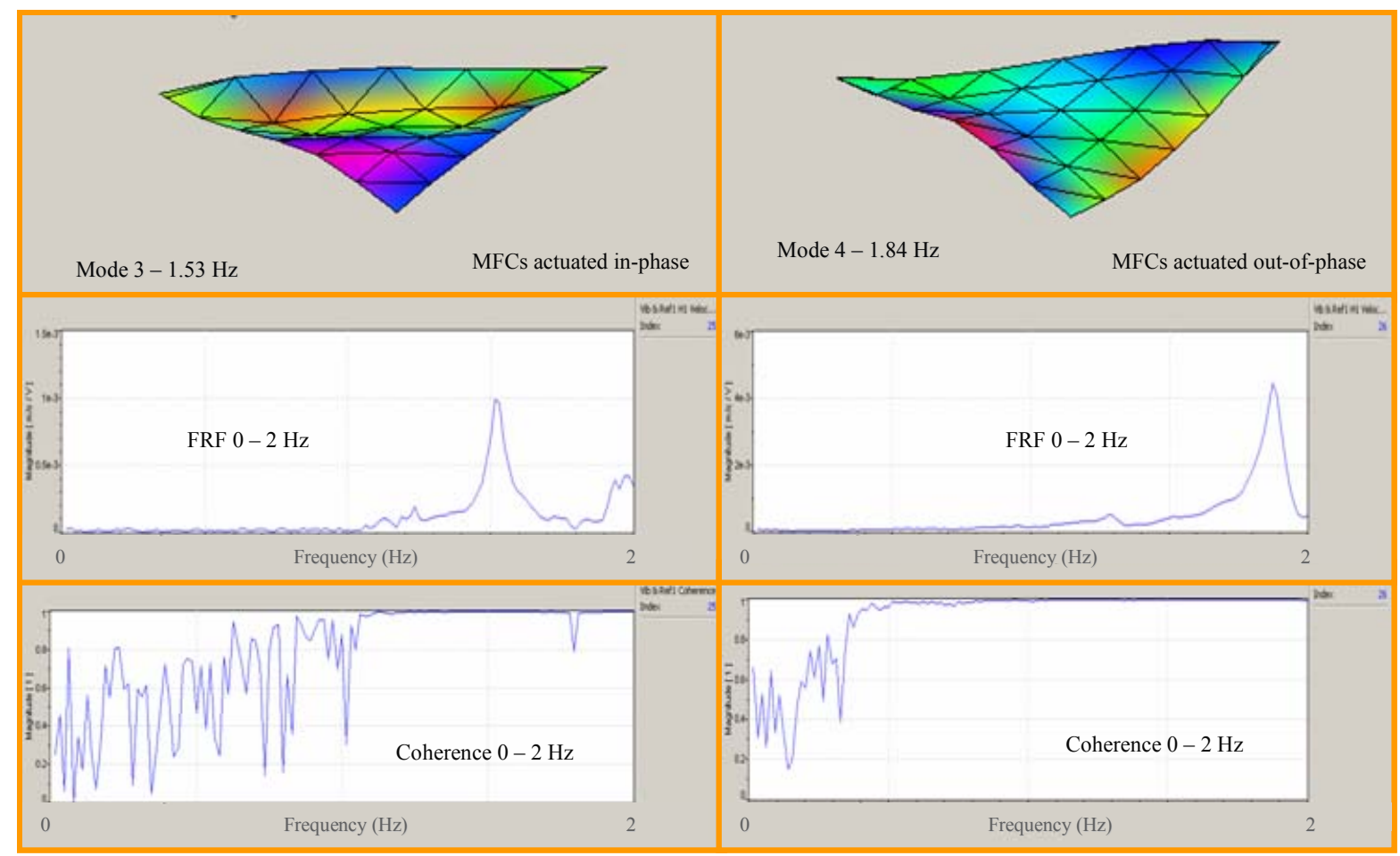

Figure 9. Coherence and Mode Shape Obtained from Test Configuration 3 


\section{Solar Sail Quadrant In-Vacuum Test Observations}

Surface-bonded piezoelectric patches were used to perform modal tests on a large thin pre-tensioned solar sail membrane in-vacuum using various excitation locations. It was shown that surface-bonded piezoelectric patches provide adequate excitation energy to obtain modal frequencies and mode shapes of a solar sail prototype. However, multiple mode shapes were difficult to obtain with a single actuator configuration and were highly dependant on selecting a suitable location to properly excite the desired modes. It is believed that further work investigating optimum multi-point excitation locations and selectively controlling the energy input to each individual actuator over various frequency bandwidths will provide better results. Further research is warranted, as this technique has traceability to planned flight test programs for system identification.

\section{Mast Ambient Tests}

A segment of a solar sail mast concept was tested in ambient atmospheric conditions using various excitation techniques, and these methods were also assessed for their ground test capabilities and potential for on-orbit flight testing.

\section{A. Description of Mast Test Article}

The mast, shown in Fig. 2, is an engineering development unit (EDU) measuring 5.4 feet long with an outer diameter of 15.5 inches. The mast has the cross sectional properties and stiffness characteristics of a mast designed for an 80-meter square solar sail. The longerons are made of extruded graphite epoxy with high stiffness characteristics and a cross section diameter of 0.096-inches. The EDU mast was provided by AEC-ABLE, and is a prototype solar sail mast they are developing as part of a NASA In-Space Propulsion development program. Langley is teamed with AEC-ABLE and tasked with developing test techniques, analysis, and on-orbit diagnostic systems. The test reported here was performed as part of a pre-test development effort to develop test techniques for a solar sail prototype AEC-ABLE has built that will need to be tested for its dynamic characteristics in a vacuum environment.

\section{B. Mast Measurement and Excitation Methods}

The test article response measurements were made with the Polytec laser vibrometer by measuring the response off a grid of retro-reflective targets as shown in Fig. 10. The test article is excited using two types of excitation methods, a non-contacting impact hammer method and unimorph MFC piezoelectric actuation. For the impact hammer method, the test article was excited using a Piezotronics PCB086B09 impact hammer which was triggered by a digital timer switch box for automated excitation. The hammer was secured to a heavy steel plate set on a platform positioned on a corner edge of the mast as shown in Fig. 11. In this configuration, the impact hammer can provide a consistent excitation input force and induce an out-of-plane disturbance on the mast. Note, that the mast has been mass loaded to reduce its natural frequencies to a level more realistic for a much larger sized mast. The FRF's from this test were computed using 6 ensemble averages and 6400 frequency lines from $0-100 \mathrm{~Hz}$.

The other actuation method used ceramic fiber based piezoelectric MFC patches bonded to the long narrow longerons near the mast root. A periodic chirp signal was used with a frequency bandwidth of 0-70 Hz. The FRF's were computed using 3 ensemble averages and 4480 frequency lines from 0 to $70 \mathrm{~Hz}$. As shown in Fig. 12, the forward two MFCs are activated out-of-phase with the back MFC to induce bending vibration near the mast root. 


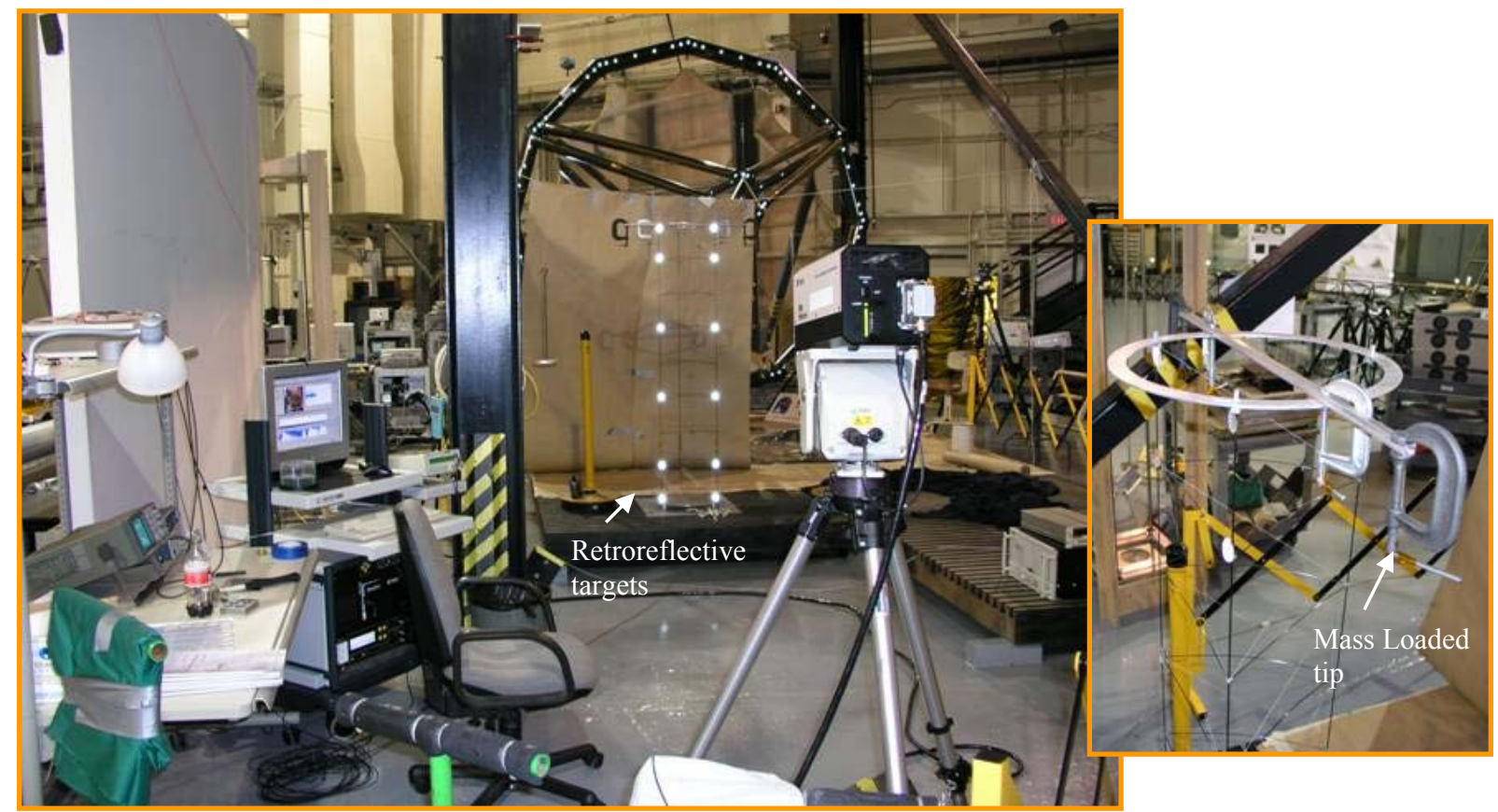

Figure 10. Mast Modal Test - General Set-up

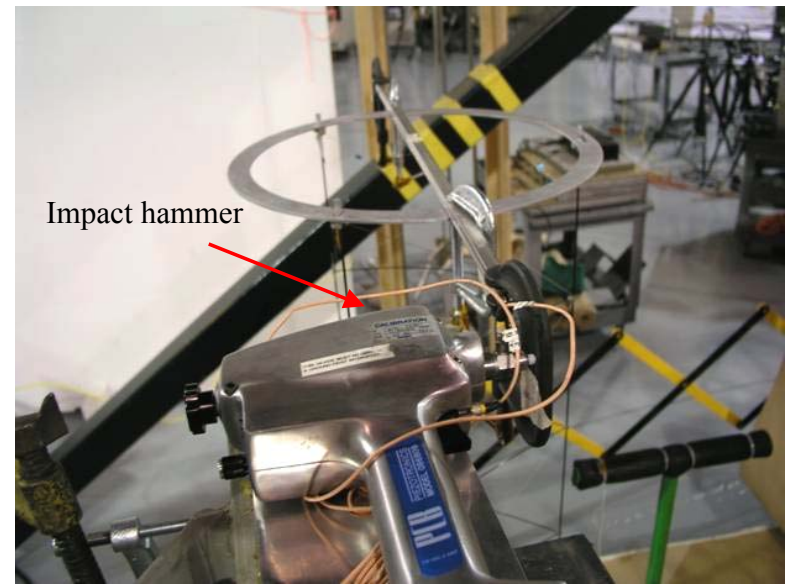

Figure 11. Impact Hammer at Mast Tip

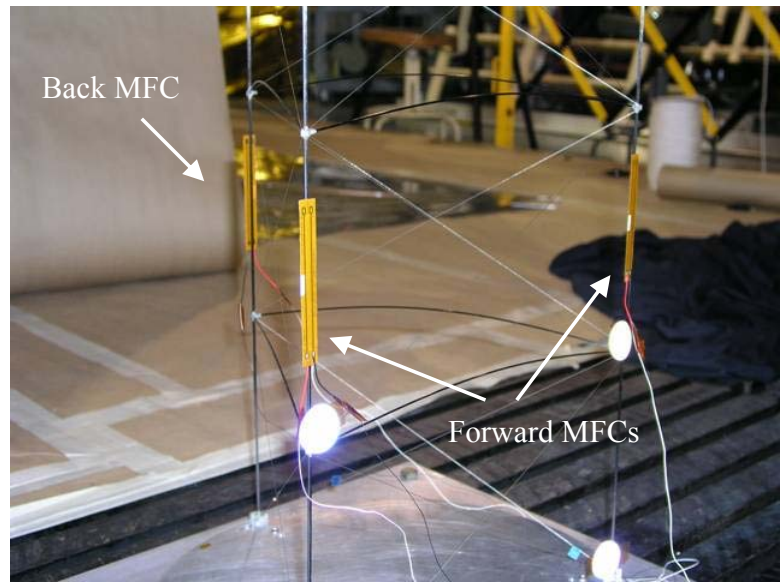

Figure 12. MFC Actuators on Mast Longerons

\section{Discussion of Mast Test Results}

The results from the MFC actuator test were very encouraging. It was observed that the MFC's could effectively identify the first two mast modes including torsion. The MFC's reacted against a very stiff longeron and only required a small surface area for bonding. The results shown in Figures 13 and 14 indicate that the modes were very well excited with good coherence at resonance. The impact hammer method is a more traditional modal testing technique and its results correspond very well with the MFC test results as shown in Fig. 15. 


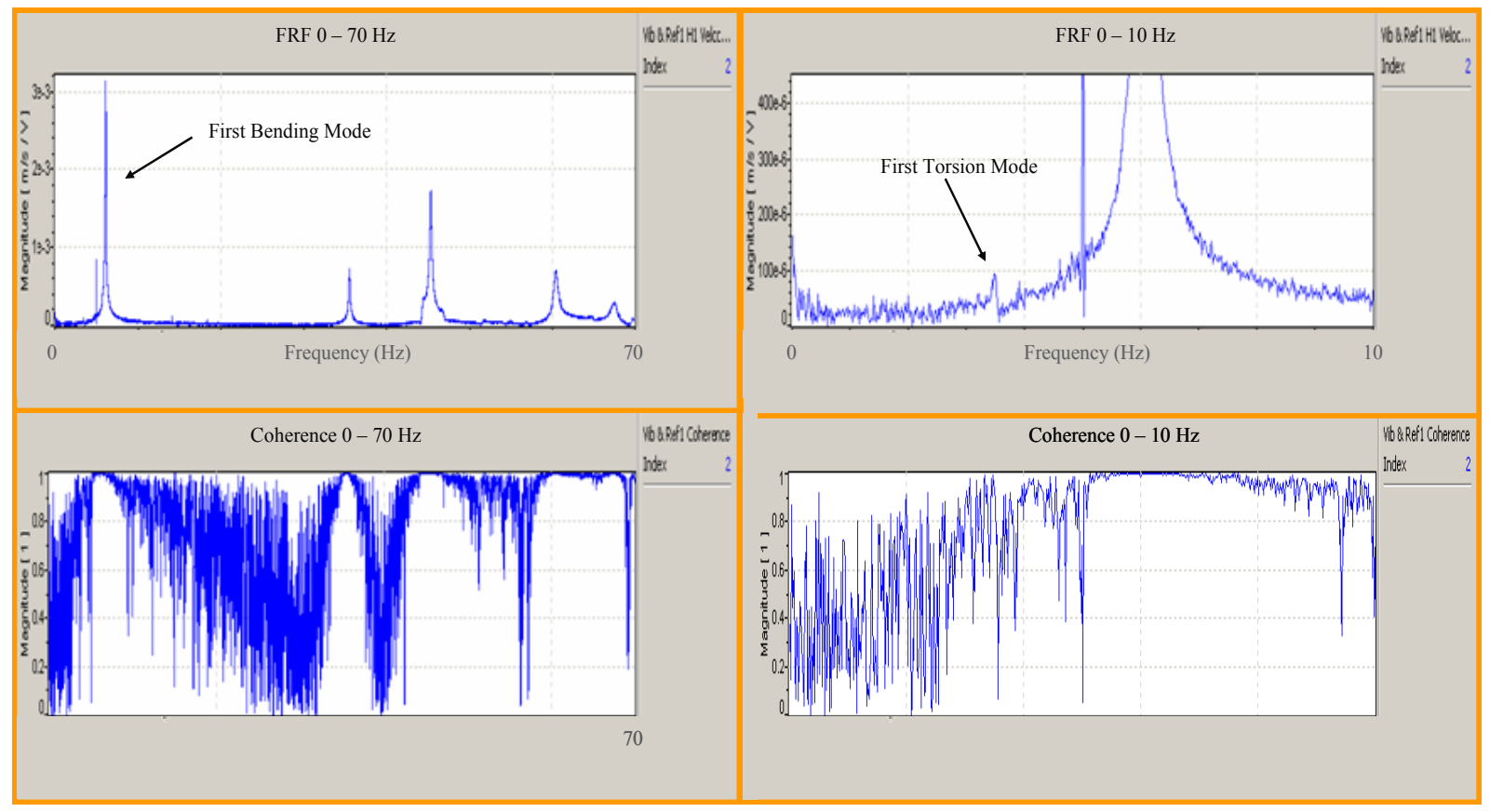

Figure 13. Mast MFC Excitation Modal Test - FRF and Coherence
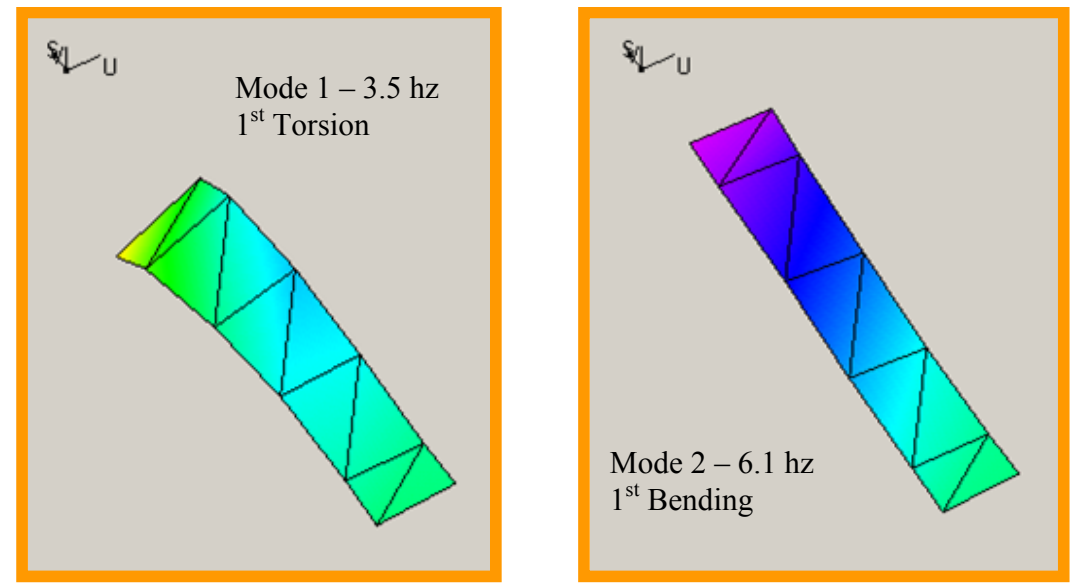

Figure 14. Mast MFC Excitation Modal Test - Mode Shapes 


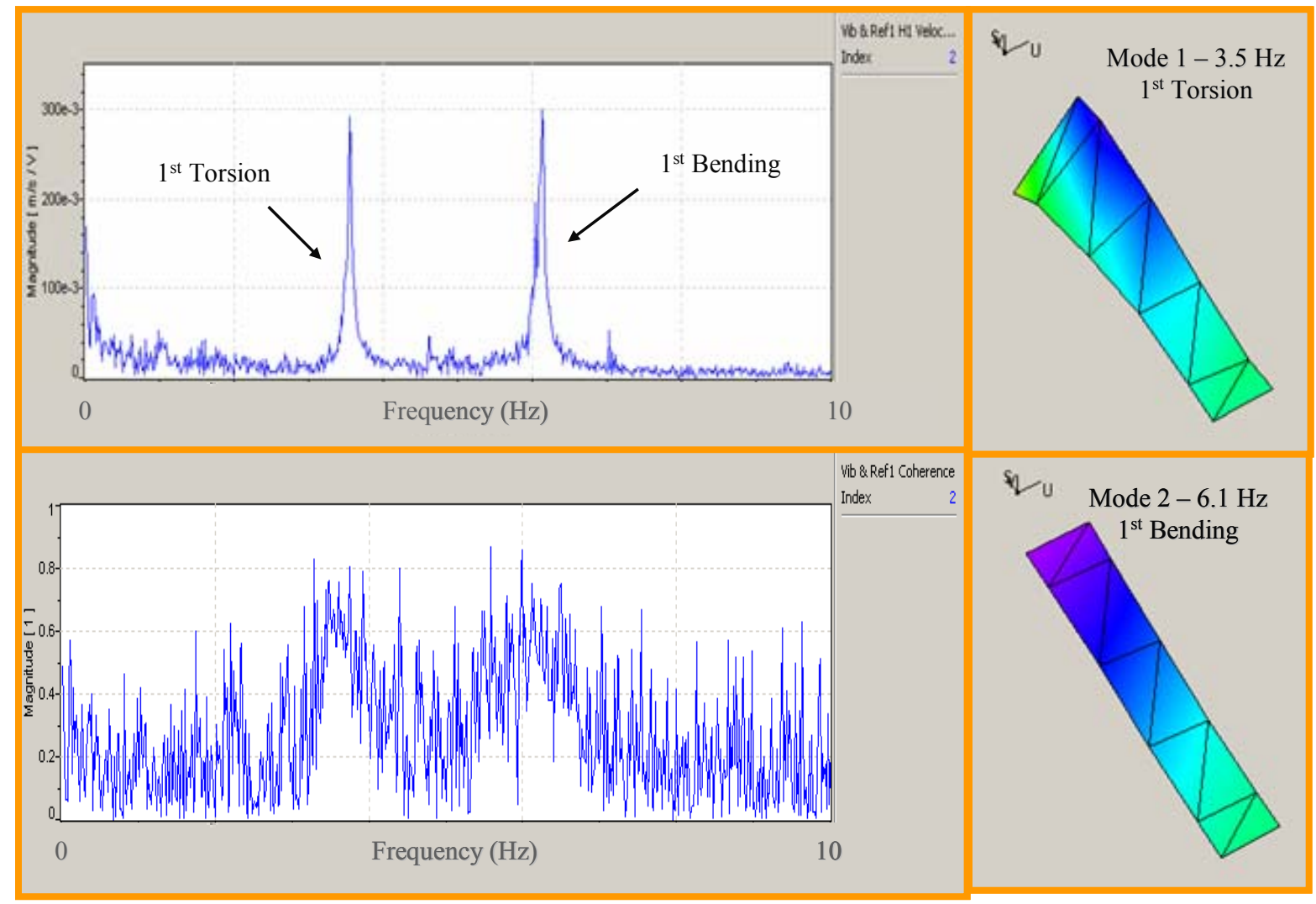

Figure 15. Mast Impact Hammer Excitation Modal Test Results

\section{Conclusions}

Surface-bonded piezoelectric patches were used to successfully perform modal tests on a large area ultralightweight solar sail membrane quadrant in-vacuum. The tests were able to properly identify the first four modes, which are important for model correlation activity. It was shown that piezoelectric actuators could also be used to characterize the modal behavior of a built up mast structure while bonded to a small surface area of a stiff longeron. In both cases, the piezoelectric actuator results were compared with other more traditional techniques for verification. Although the magnetic exciter and impact hammer methods have an advantage in performing structural dynamic identification on large ultra-lightweight gossamer structures such as solar sails due to their non-contacting nature, these methods could not be used in future planned flight test programs for on-orbit validation. Only during on-orbit validation can these structures be properly characterized, free of gravity. The MFC's, due to their light weight design and because they can be manufactured in many diverse ways and be configured for embedding in these structures offer a very attractive alternative for on-orbit validation of gossamer structures.

\section{Acknowledgements}

The authors would like to thank Dave Murphy and Brian Macy of AEC-ABLE for helpful discussions and for providing the mast EDU test article.

\section{References}

${ }^{1}$ Chmielewski, A. B., Moore, C., and Howard, R., “The Gossamer Initiative,” IEEE paper 0-7803-5846-5/00, January 2000.

${ }^{2}$ Johnston, J. and Lienard, S., "Modeling and Analysis of Structural Dynamics for a One-Tenth Scale Model NGST Sunshield," Proceedings of the $42^{\text {nd }}$ AIAA/ASME/ASCE/AHS/ACS Structures, Structural Dynamics, and Materials Conference, Seattle, WA, April 16-19, 2001, AIAA-2001-1407.

${ }^{3}$ Murphy, D., Macy, B., and Gaspar, J., "Demonstration of a 10-m Solar Sail System", $45^{\text {th }}$ AIAA Structures, Structural Dynamics, \& Materials Conference, $5^{\text {th }}$ Gossamer Spacecraft Forum, 2004. 
${ }^{4}$ Murphy, D., Murphey, T., and Gierow, P., "Scalable Solar-Sail Subsystem Design Concept”, AIAA Journal of Spacecraft and Rockets, Volume 40, No. 4, pp. 539-547, July-August 2003.

${ }^{5}$ Murphy, D., Trautt, T., McEachen, M., Messner, D., Laue, G., and Gierow, P., "Progress and Plans for System Demonstration of a Scalable Square Solar Sail," AAS 04-105, 14 ${ }^{\text {th }}$ AAS/AIAA Space Flight Mechanics Meeting, 2004.

${ }^{6}$ Slade, K. N., Belvin, W. K., Tetlow, T. K., "Dynamic Characterization of a Subscale Solar Sail using Non-Contacting Excitation and Sensing," Proceedings of the $44^{\text {th }}$ AIAA/ASME/ASCE/AHS/ACS Structures, Structural Dynamics, and Materials Conference, Norfolk, VA, April 7-10, 2003, AIAA-2003-1744.

${ }^{7}$ Wilkie, W. K., Bryant, G. R., High, J. W. et al., "Low-Cost Piezocomposite Actuator for Structural Control Applications," Proceedings, SPIE $7^{\text {th }}$ Annual International Symposium on Smart Structures and Materials, Newport Beach, CA, March 5-9, 2000.

${ }^{8}$ Gaspar, J. L., Pappa, R. S., “Membrane Vibration Tests Using Surface-Bonded Piezoelectric Patch Actuation,” Proc. of the $21^{\text {st }}$ International Modal Analysis Conference, Kissimmee, Florida, February 3-6, 2003. 